\title{
A cartografia de síntese e as estruturas verticais e horizontais da paisagem em ambientes urbanos suscetíveis à inundação
}

\section{Synthesis cartography and the vertical and horizontal landscape structures in urban environments susceptible to flooding}

\author{
Andrea Zacharias ${ }^{* 1} \bowtie\left(D\right.$, Ana Luisa Teixeira ${ }^{2} \bowtie(0)$, Silvia Elena Ventorini ${ }^{2} \bowtie(1)$ \\ André Barbosa Ribeiro Ferreira $1 \bowtie\left(D\right.$, Thiago Gonçalves Santos ${ }^{2} \bowtie(D)$ \\ Universidade Estadual Paulista Júlio de Mesquita Filho, Câmpus de Ourinhos/Rio Claro, São \\ Paulo, Brasil \\ Departamento de Geociências, Universidade Federal de São João Del Rei, São João Del Rei, \\ Minas Gerais, Brasil \\ E-mail: ana_luisateixeira@hotmail.com (ALT); sventorini@ufsj.edu.br (SEV); \\ abr.ferreira@unesp.br (ABRF): thiiaguim.13@gmail.com (TGS) \\ *E-mail para correspondência: andrea.zacharias@unesp.br
}

Recebido (Received): 05/11/2020

Aceito (Accepted): 18/05/2021

Resumo: Este artigo apresenta uma proposta metodológica para a Cartografia de Síntese, considerando as dimensões (x, y, z, t), as estruturas verticais (escalas taxonômicas) e as estruturas horizontais (componentes e atributos geográficos) para a representação espacial da dinâmica da paisagem urbana, assim como a espacialização das áreas com suscetibilidades às inundações a partir de dois cenários gráficos (anos de 1989 e 2020), como apoio às políticas públicas municipais. O estudo adota como recorte espacial o Setor Censitário Colônia do Marçal, localizado no município de São João del-Rei, estado de Minas Gerais, Brasil. E, a fundamentação teórico-metodológica teve como base a Análise Multicritério de Decisão, associada à Análise Hierárquica de Processo (AHP) no ambiente SIG, com a perspectiva de aplicar modelagens em áreas suscetíveis às inundações e enchentes. Os procedimentos consistiram em elaboração de mapas temáticos; álgebra de mapas e elaboração do cenário gráfico da Cartografia de Síntese, considerando as estruturas verticais e horizontais do ambiente na paisagem urbana. Os dois modelos espaciais temporais apresentam áreas de muito alta suscetibilidade em alguns locais em comum, já que - apesar da expansão da área urbana a planície de dois rios de grande porte não alterou os cenários, mesmo com a ampliação da quantidade de construções urbanas. Constata-se que em torno de outros canais fluviais de menor dimensão, as classes alta e muito alta suscetibilidades às inundações são evidenciadas em razão da dinâmica natural de inundação. O cenário gráfico da síntese apresenta a influência da dinâmica dos fluxos de energia, matéria e informação (EMI) da área no estado ambiental da paisagem, observados pelas estruturas verticais e estruturas horizontais.

Palavras Chaves: Análise Hierárquica de Processo; Análise Multicritério de Decisão; Mapa Temático.

Abstract: This article presents the methodological proposal for Synthesis Cartography, considering the dimensions $(x, y, z, t)$ and the vertical (taxonomic scales) and horizontal (components and geographical attributes) dimensions for the spatial representation of the urban landscape dynamics, as well as the spatialization of flood susceptibles areas from two graphic scenarios (years 1989 and 2020), as support to municipal public policies. The study adopts the Census Sector Colônia do Marçal, located in the municipality of São João del-Rei, state of Minas Gerais, Brazil as a spatial clipping.The theoreticalmethodological foundation was based on research with Multicriteria Decision Analysis for the application of modeling of areas susceptible to floods and inundations. The procedures consisted of preparing thematic algebra maps and elaboration of the graphic scenario of the Synthesis Cartography, considering the environment vertical and horizontal structures in the urban landscape. The two time-space models present areas of very high susceptibility in some common places, despite the expansion of the urban area, two large rivers plains did not alter the scenarios, even with the expansion of the amount of urban constructions. It is 
observed that, around other smaller fluvial channels, the classes high and very high susceptibilities to floods are because of the natural dynamics of flooding. The graphical scenario of the synthesis shows the influence of the energy, matter and information dynamics (EMI) flows of the area on the landscape environmental state, observed by vertical and horizontal structures.

Keywords: Hierarchical Process Analysis; Multicriteria Decision Analysis; Thematic Map.

\section{Introdução}

O processo de urbanização modifica o equilíbrio e a dinâmica dos fenômenos naturais, resultando em impactos ambientais (GARCIA et al., 2020), prejuízos sociais, econômicos (GIRÃO; CORRÊA, 2004) e perdas de vidas em diferentes regiões e países. A crescente degradação do solo ocasionada por ocupações irregulares, crescimento das cidades e impermeabilização dos solos, aumento da população, práticas agrícolas inadequadas, inundações e processos erosivos provocados pelo desmatamento, canalização de rios, assoreamento e entupimento das calhas dos rios, entre outros problemas ambientais, têm fornecido dados importantes para os estudos que viabilizam o levantamento da dinâmica atual do uso e ocupação da terra no limite territorial municipal (ZACHARIAS, 2006, 2010; AUMOND et al., 2012; SANDER et al., 2012; GARCIA et al., 2020; CAVALCANTI, 2013; BRAZ, 2020). Tais ações ganharam ainda mais expressividade com as novas políticas de gestão urbana (Lei Federal $n^{\circ} 12.608 / 2012$ ), publicadas pela Política Nacional de Proteção e Defesa Civil (PNPDEC).

Como forma de pensar e planejar a cidade, essas políticas corroboram com importantes alterações nas Leis, para a escala municipal, por meio do Estatuto da Cidade (Lei Federal $n^{\circ} 10.257 / 01$ ) e da Lei de Parcelamento do Solo (Lei Federal $n^{\circ}$ 6.766/79), os quais passam a ter novas diretrizes compostas de ações que incorporam a questão das áreas de risco e população exposta ao risco de desastres, transferindo aos municípios as competências de identificar e mapear áreas suscetíveis às ocorrências de desastres; planejar e gerenciar ações com intervenção e relocação de populações de áreas de risco; propor medidas de drenagem urbana para prevenção e mitigação de impactos de desastres; identificar diretrizes para a preservação e ocupação das áreas verdes municipais, com vistas à redução da impermeabilização das cidades. São essas novas Políticas Urbanas, representadas, principalmente, por meio do Plano Diretor, que passam a definir áreas de riscos coibindo a ocupação e o loteamento dessas áreas, uma parte da iniciativa necessária para prevenir e minimizar os desastres, além de promover a criação de cidades mais resilientes (REANI et al., 2020).

Neste sentido, os métodos de Análise Multicritério de Decisão (AMD), associados à Análise Hierárquica de Processo (AHP) no ambiente SIG, têm sido utilizados para modelar fenômenos hidrológicos que ocorrem em paisagens urbanas, mostrando-se assim como um eficiente caminho metodológico para orientar tomadas de decisões, no planejamento urbano, que amenizam problemas socioambientais (SANTOS; VENTORINI, 2017; 2018). A partir de informações disponibilizadas em mapas temáticos, seus desafios consistem em atribuir um método de análise espacial baseada em álgebra de mapas e elaboração de modelos descritivos e hierárquicos dos diferentes ambientes da paisagem. O procedimento baseia-se na atribuição de pesos (influências) nos mapas e valores numéricos em suas classes, possibilitando integrar peculiares topográficas, hidrológicas, ecológicas, sociais, econômicas, culturais, dentre outras. Ressalta-se, deste modo, a importância de considerar a heterogeneidade da área urbana, não representando-a em um único polígono homogêneo na associação das informações com o mapa de uso da terra (MATERNO; BRITO, 2020; OGATO et al., 2020).

Assim, tomando como base a Lei $\mathrm{n}^{\circ} 12.608 / 2012$, a qual determina a criação de um sistema de informações e monitoramento de desastres, além de outas providências, este estudo aplica os métodos supracitados em um Setor Censitário da cidade de São João del-Rei, Minas Gerais - Brasil com os objetivos de: a) apresentar uma proposta metodológica de cenário gráfico para a Cartografia de Síntese identificando os diferentes estados ambientais do setor censitário, considerando por um lado as dimensões (x, y, x, t) e, por outro, as estruturas verticais (escalas taxonômicas) e horizontais (componentes e atributos geográficos) da paisagem urbana; b) espacializar as áreas com suscetibilidades aos riscos hidrológicos por inundações na paisagem urbana do setor, a partir de cenários gráficos compostos por modelos espaciais (cartografia dinâmica) que retratem suas condições no passado (1989) e no presente (2020), e; c) elaborar o mapa síntese como forma de auxiliar as políticas públicas municipais com diagnósticos para subsidiar as discussões sobre o ordenamento territorial em áreas de potencial desequilíbrio ambiental e que necessitam de monitoramento pelo avanço urbano. 


\section{Materiais e métodos}

\section{1. Área de estudo}

O Setor Censitário Colônia do Marçal abrange 13 bairros localizados na porção nordeste do município de São João del-Rei, Minas Gerais. A amplitude altimétrica local é de 240 metros (m). As áreas com menores altimetrias (abaixo de $890 \mathrm{~m}$ ) e graus de declividade $\left(0^{\circ}\right)$ localizam-se na planície de inundação do Rio Carandaí e entroncamento com Rio das Mortes. As áreas mais elevadas localizam-se na Serra de São José (1140m), com declividades acima 59 . Nas áreas com altimetrias intermediárias localiza-se a maior parte da área residencial do bairro (Figura 1).

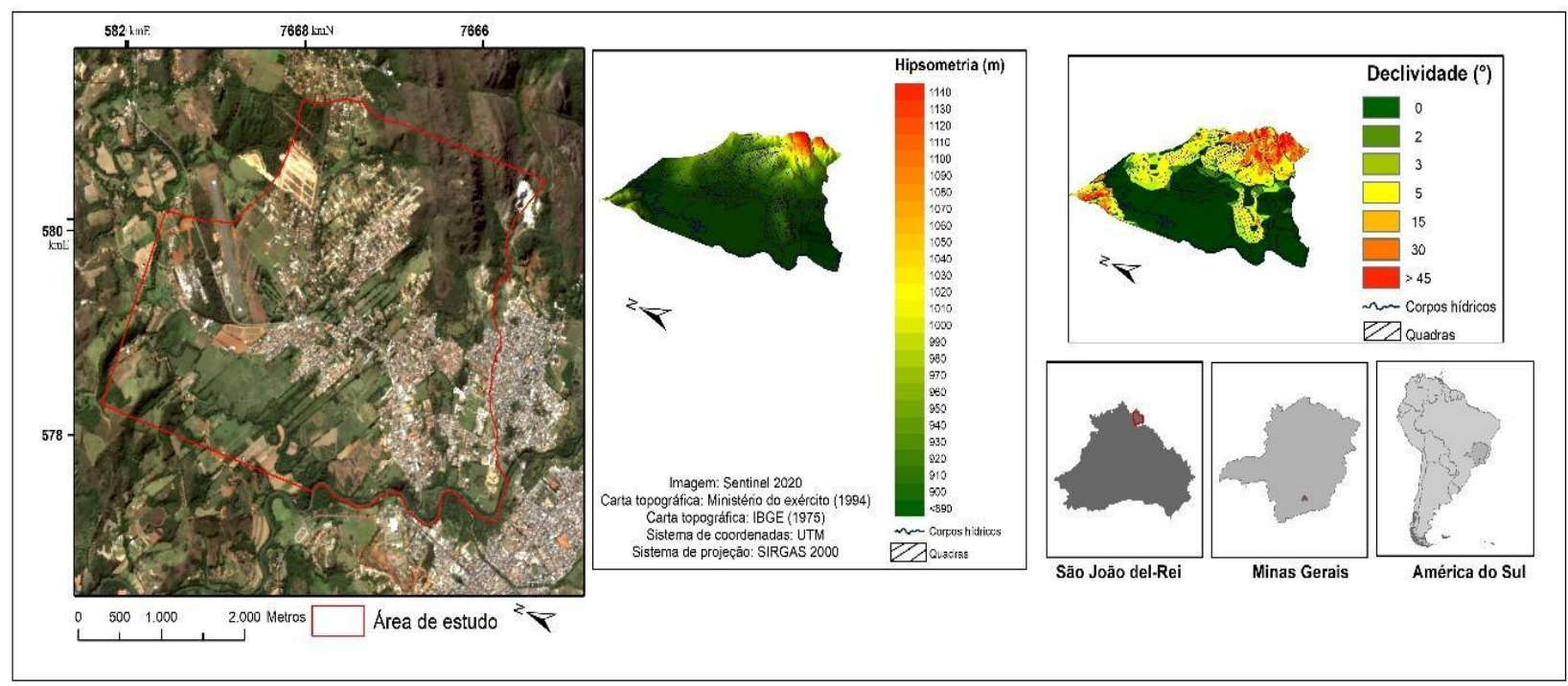

Figura 1: Localização da Área de Estudo. Fonte: Autores (2020).

O crescimento populacional no setor em questão, entre os anos de 1980 e 2010, foi de 101,6\%, (de 4.953 para 9.986 habitantes) (IBGE, 1980, 2010). A expansão do perímetro urbano, entre o período de 1989 a 2020, foi de $320 \%\left(1,26 \mathrm{~km}^{2}\right.$ para $\left.5,3 \mathrm{~km}^{2}\right)$ e em direção às áreas com menores altitudes e declividades, próximas às planícies de inundação dos Rios Carandaí e das Mortes, além disso, canais de menor porte foram aterrados ou canalizados ao longo dos terrenos. Esta expansão também ocorreu em direção à Serra de São José, impermeabilizando áreas com maiores declividades e acelerando os fluxos de águas em direção às menores declividades, também impermeabilizadas. Em ambas as áreas, com declividades distintas, a capacidade de infiltração das águas no solo foi reduzida, os cursos d'água modificados e, somado a isso, não foram implementadas obras eficientes de drenagem pluvial. A cada período chuvoso, a população vivencia os transtornos ocasionados pela inundação e alagamento de ruas e residências, o que gera prejuízos sociais e econômicos. A área de estudo reflete situações que ocorrem em diversas cidades brasileiras, fato que justifica sua escolha.

\subsection{Caminho metodológico}

A modelagem ambiental dos padrões espaciais teve como fundamentação teórico-metodológica os princípios da Análise Hierárquica de Processos (AHP) proposta por Saaty $(2005,2006)$ e Gigović et al. (2009); Rahmati et al. (2015); Santos e Ventorini (2017ab, 2018); Hoang et al., (2020); Ogato et al., (2020), dentre outros que utilizam a Análise Multicritério de Decisão (AMD) e AHP em ambientes de SIG para aplicação de modelagens de áreas propícias às inundações e enchentes.

\subsubsection{Elaboração das bases cartográficas para os mapas temáticos}

\section{a) Bases (cartográfica e temáticas)}

A base de mapas temáticos foi construída a partir de: a) Carta Topográfica em escala 1:25.000, (Folha MI 2644/1/1994, equidistância 10m); b) Carta Topográfica em escala 1:50.000, (Folha SF-23-X-C-II-2/1975, equidistância 20m), c) Imagem Landsat 5 (Path Row 218/75), resolução espacial 30 metros; d) Imagem Sentinel (Tile T23KNS), resolução espacial 10 metros; e) base em shapefile da área urbana do Censo Demográfico (IBGE, 2010) e; f) mapas de áreas de riscos às inundações disponibilizados no Plano de 
Contingência da Defesa Civil do Município de São João del-Rei (DEFESA CIVIL, 2015). Para a elaboração das bases (cartográfica e mapas temáticos), o SIG utilizado foi o software ArcGis 10.7, 10.8.1 e extensões do Arc Toolbox, em que os mapas temáticos foram reclassificados, em 5 classes, conforme o grau de influência no fenômeno modelado em: (1) muito baixa influência; (2) baixa influência; (3) média influência; (4) alta influência e; (5) muito alta influência.

\section{b) Modelo Numérico do Terreno - MNT}

O MNT foi convertido em raster com pixel de 10m e reclassificado em: (1) muito baixa influência; para as altitudes acima de 910 metros; (3) média influência para as elevações de 900 a 910 metros; (4) alta influência para 890 a 900 metros e; (5) muita alta influência para as altitudes abaixo de 890 metros. Tais influências foram estabelecidas considerando o controle exercido pela altimetria sobre o movimento, direção e extrapolação das águas dos rios e córregos, assim como no fluxo de escoamento na superfície (GIGOVIC et al., 2009; OGATO et al., 2020).

\section{c) Mapa Clinográfico (Declividade)}

O MNT original, sem reclassificação, foi utilizado para a elaboração do mapa de declividade (em graus) a partir da ferramenta Slope. O atributo declividade possui relação direta com o fenômeno em análise, pois condiciona aceleração ou retenção do escoamento de acordo com a inclinação (GIGOVIC et al., 2009; RIMBA et al., 2017; OGATO et al., 2020). Desse modo, a reclassificação do mapa de declividade foi assim estabelecida: declividades entre $0^{\circ}$ e $2^{\circ}$ reclassificadas em (5) - muito alta influência; entre $2^{\circ}$ e $3^{\circ}$ reclassificadas em (3) - média influência e; (1) - muito baixa influência para declividades a partir de $3^{\circ}$.

\section{d) Mapa de Hidrografia}

Para a elaboração do mapa de hidrografia utilizou-se a carta topográfica, na escala de 1:25.000 (de 1994), em conjunto com a carta na escala de 1:50.000 (de 1975), pois a mais recente não contém a representação da hidrografia completa (canalizada ou aterrada). A veracidade das informações mapeadas foi verificada em campo e por meio de análise de imagem do satélite Sentinel.

A partir da hidrografia elaborou-se um mapa de distâncias euclidianas utilizando-se das ferramentas Buffer e Multiple Ring Buffer. Para os córregos adotou-se a distância de 30 metros a partir de cada margem, com base na Lei n 12.651, de 25 de maio de 2012 (Brasil, 2012) e para os rios de maior porte (Carandaí e das Mortes) foram consideradas as distâncias mapeadas pelo Serviço Geoló gico do Brasil Serviço - CPRM (DEFESA CIVIL, 2015), cujos intervalos variaram conforme a alteração no tamanho da planície de inundação. As distâncias euclidianas foram 300, 400 e 700 metros, partindo-se do pressuposto que áreas mais próximas dos corpos hídricos são as primeiras e mais afetadas por inundações (FERNANDEZ; LUTZ, 2010; FADHIL et al., 2020). A reclassificação das classes de distâncias dos corpos hídricos foi: (5) muita alta influência para as distâncias 0 até 30 (córregos) e 0 até 300 metros (rios); (4) alta influência para as distâncias entre 300 até 400 metros; (3) média influência para as distâncias entre 400 até 700 metros e; (1) muito baixa influência o restante das distâncias que compõem a área de estudo.

\section{e) Mapas de Uso e cobertura da Terra - UCT (1989 e 2020)}

O UCT dos anos de 1989 e 2020 foi delimitado a partir de imagens dos satélites Landsat 5, e Sentinel 2, respectivamente. A utilização de dois produtos com características diferentes é justificada pela disponibilidade dos mesmos, visto que, para o ano de 1989 não há imagens gratuitas e de melhor resolução disponíveis. As diferenças espectrais e espaciais dos dois produtos não interferiram na elaboração do mapa de UCT, pois a classificação não utilizou segmentação automática e valor do nível digital dos pixels. $\mathrm{O}$ processo foi efetuado a partir da fotointerpretação das imagens na composição colorida $3 \mathrm{~B}$, 4G e $5 \mathrm{R}$ (Landsat 5) e 2B, 3Ge 4R (Sentinel 2).

A partir das chaves de interpretação de imagens (textura, cor, rugosidade, etc.) vetorizou-se manualmente as classes de UCT. No processo identificou-se seis classes de legenda: a) loteamentos, b) áreas com poucas residências; c) áreas com muitas residências; d) áreas com vegetação natural, e) mineração, pastagem e agricultura e; f) corpos hídricos. As classes de UCT do foram validadas com dados coletados em campo e dados secundários.

Os vetores de UCT foram convertidos para o formato raster com pixels de $10 \mathrm{~m}$ e as classes reclassificadas em: (1) muito baixa influência - afloramento rochoso e vegetação natural; (2) baixa influência 
- para pastagem, agricultura e mineração; (3) média influência - para os loteamentos; (4) - alta influência para áreas com poucas residências; (5) muita alta influência - para áreas residenciais. As áreas classificadas como corpos hídricos (pequenas lagoas) foram reclassificadas como Restritas (0) - tendo influência nula.

\subsubsection{Aplicação do Processo Hierárquico Analítico - AHP}

\section{a) Critérios e mensuração das matrizes de consistências dos julgamentos}

A matriz de julgamento $4 x 4$, referente à quantidade de variáveis determinadas e organizadas em ordem de linhas (i) e colunas (j), a partir dos critérios da AHP e composta pelo número de variáveis (n) e a partir dos critérios analisados (C), foi construída tendo como base a AHP (Tabela 1) proposta por Saaty (2005, 2006).

Tabela 1: Classificação da AHP

\begin{tabular}{ll}
\hline Pesos & \multicolumn{1}{c}{ Análise Hierárquica de Processos (AHP) } \\
$\mathbf{1}$ & Definição \\
$\mathbf{3}$ & Importância igual: Os dois fatores contribuem igualmente para o objetivo. \\
$\mathbf{5}$ & Importância moderada: Um fator é ligeiramente mais importante que o outro. \\
$\mathbf{7}$ & Importância demonstrada: Um fator é claramente mais importante que o outro. \\
& prática. \\
$\mathbf{9}$ & Importância extrema: A evidência que diferencia os fatores é da maior ordem possível (9). \\
$\mathbf{2 , 4 , 6 , 8}$ & Valores intermediários entre julgamentos: Possibilidade de compromissos adicionais. \\
\hline
\end{tabular}

Fonte: Saaty (2008, p. 86), adaptado pelos autores (2020)

A comparação corresponde a $\mathbf{a}_{\mathrm{ij}}$, determinado a partir da análise da variável importante para o objetivo a ser modelado. Na montagem da matriz as relações são recíprocas entre as variáveis, considerando que $\mathbf{a}_{\mathbf{i j}}=\mathbf{x}$, $\operatorname{logo}, \mathbf{a}_{\mathbf{j i}}=\mathbf{1} / \mathbf{x}$. Em diagonal a comparação na matriz ocorre com o valor de 1 - importância igual, por ser a mesma variável (Saaty, 2005, 2006; Vargas, 2010; Ribeiro e Alves, 2016; Materano e Brito, 2020). A Tabela 2 ilustra a matriz elaborada para a modelagem do Setor Colônia do Marçal.

Para determinar as variáveis, tomou-se como referência: Florenzano (2008), Dias e Silva (2014), Ceconi (2018), Hoang et al. (2020), Rahmati et al. (2020), Ogato et al. (2020) e Materano e Brito (2020). Estes pesquisadores estabelecem relações entre os elementos os geográficos - hipsometria, declividade, distância euclidiana entre os corpos hídricos e uso da terra - e as ocorrências de inundações. Em complemento, foram coletados dados primários em campo e analisadas informações disponibilizadas pela Defesa Civil Municipal $(2013,2015)$.

Tabela 2: Matriz de Julgamento da AHP

\begin{tabular}{ccccc}
\hline $\mathbf{C}$ & $\mathbf{n}_{\mathbf{1}}$ & $\mathbf{n}_{2}$ & $\ldots$ & $\mathbf{n}_{\mathbf{n}}$ \\
\hline $\mathrm{n}_{1}$ & 1 & $\mathrm{a}_{12}$ & $\ldots$ & $\mathrm{a}_{1 \mathrm{n}}$ \\
$\mathrm{n}_{2}$ & $1 / \mathrm{a}_{21}$ & 1 & $\ldots$ & $\mathrm{a}_{2 \mathrm{n}}$ \\
$\mathrm{n}_{\mathrm{n}}$ & $1 / \mathrm{a}_{\mathrm{n} 1}$ & $1 / \mathrm{a}_{\mathrm{n} 2}$ & & 1 \\
\hline
\end{tabular}

Fonte: Ribeiro e Alves (2016), adaptado pelos autores (2020)

A partir da matriz de julgamento, realizou-se o somatório dos valores de todas as colunas $\left(\Sigma \mathrm{n}_{\mathrm{j}}\right)$ das variáveis julgadas e, posteriormente, a partir deste total realizou-se o processo de normalização da matriz $\left(\mathrm{V}_{\mathrm{i}}\right)$ dado a partir dos valores de cada linha $\left(\mathrm{n}_{\mathrm{j}}\right)$ em razão da $\Sigma \mathrm{n}_{\mathrm{j}}($ Equação 1):

$$
V i=n i / \Sigma n j
$$

Em que: Vi, é o valor de normalização;

$\mathrm{n}_{\mathrm{i}} \mathrm{o}$ valor de cada linha e

$\Sigma \mathrm{n}_{\mathrm{j}}$ a somatória das colunas de cada variável.

A matriz normalizada foi verificada a partir do somatório dos valores de cada coluna cujo resultado de cada variável foi 1 . Posteriormente, calculou-se o vetor de prioridade em porcentagem (\%) por meio da soma de todas as linhas da matriz $\left(\sum \mathrm{a}_{\mathrm{i}}\right)$. O resultado foi obtido pela média aritmética dos valores que se refere ao percentual relativo das prioridades traçadas a partir do objetivo de estudo (Equação 2). Segundo os critérios 
elencados por Saaty $(2005,2006)$, a soma dos vetores de prioridade deve ser igual a 1 e, em sua transformação para porcentagem, igual a $100 \%$.

$$
\mathbf{V}_{\mathbf{p}}=\Sigma \mathbf{a}_{\mathbf{i}} / \mathbf{n}
$$

Em que: Vp é o vetor de prioridades, aai, a somatória das linhas normalizadas e n, o número de variáveis.

Por fim, adotou-se os parâmetros estipulados por Saaty (2005) e calculou-se a consistência dos valores atribuídos pelos julgamentos entre as variáveis da matriz de comparação gerada, considerando que o valor de tolerância máxima deve ser igual ou menor $10 \%(0,10)$ para comprovar sua consistência. Calculou-se o maior autovalor da matriz de julgamento ( $\lambda \mathrm{Max}$ ), somando as linhas da matriz normalizada ( $\Sigma$ ai) pelo número (n) de variáveis julgadas. A partir desses valores, calculou-se o Índice de Consistência (IC), conforme mostra a Equação 3.

$$
\text { IC }=(\lambda M a ́ x-n) /(n-1)
$$

A Razão de Consistência (RC) foi obtida a partir do Índice Aleatório (IA), proposto por Saaty (2006), e corresponde aos valores dados à consistência de uma matriz recíproca gerada, aleatoriamente, em uma escala de 1 a 9, apresentado na Tabela 3. A veracidade dos julgamentos atribuídos pela matriz de comparação foi obtida pelo RC (Equação 4), em que os valores de inconsistência devem ser menores ou iguais a 0,10 (Saaty,2005). A Tabela 4 ilustra a matriz de julgamento elaborada para a modelagem das áreas suscetíveis às inundações no Setor Censitário Colônia do Marçal.

$$
\text { RC }=\text { IC/IA }
$$

Eq.4

Tabela 3: Índices aleatórios em matrizes para AHP

\begin{tabular}{cccccccccccc}
\hline $\begin{array}{c}\text { Tamanho da } \\
\text { matriz }\end{array}$ & $\mathbf{1 x 1}$ & $\mathbf{2 \times 2}$ & $\mathbf{3 x 3}$ & $\mathbf{4 x 4}$ & $\mathbf{5 x 5}$ & $\mathbf{6 x 6}$ & $\mathbf{7 x 7}$ & $\mathbf{8 x 8}$ & $\mathbf{9 x 9}$ & $\mathbf{1 0 x 1 0}$ & $\mathbf{1 1 x 1 1}$ \\
\hline $\begin{array}{c}\text { Valores } \\
\text { aleatórios }\end{array}$ & 0 & 0 & 0,58 & 0,90 & 1,12 & 1,24 & 1,32 & 1,41 & 1,45 & 1,49 & 1,54 \\
\hline \multicolumn{1}{c}{ Fonte: Saaty $(2006$, p. 4), adaptado pelos autores $(2020)$} &
\end{tabular}

Tabela 4: Matriz de Julgamento para a Modelagem das áreas susceptíveis às inundações

\begin{tabular}{lcccc}
\hline Critérios & Declividade & DCH & Hipsometria & UCT \\
\hline Declividade & 1 & 2 & 2 & 3 \\
Distância dos Corpos Hídricos (DCH) & 0,5 & 1 & 2 & 2 \\
Hipsometria & 0,5 & 0,5 & 1 & 2 \\
UCT & 0,33 & 0,5 & 0,5 & 1 \\
\hline Soma & 2,33 & 4,00 & 5,2 & 8,00 \\
\hline
\end{tabular}

Fonte: Autores (2020)

\section{b) Elaboração da modelagem ambiental (Álgebra de Mapas)}

Concluído os procedimentos para gerar os modelos AMD e AHP, utilizou-se a ferramenta Weighted Overlay do ArcMap para a reclassificação dos atributos dos mapas. Tomou-se como base as considerações de Gigovic et al. (2009); Rahmati et al. (2020); Ogato et al. (2020), os quais atribuem valores numéricos de 1 a 5 para as classes de cada mapa, conforme suas importâncias no fenômeno ambiental modelado, assim como os pesos (influências) encontrados na matriz normalizada para cada mapa, associando: (1) muito baixa influência; (2) baixa influência; (3) média influência; (4) alta influência; (5) muito alta influência. A Equação 5 ilustra o procedimento em ambiente SIG e a Tabela 5 as influências e pesos adotados.

$\left(\mathrm{DEC}^{*} 42\right)+\left(\mathrm{DCH}^{* 27}\right)+(\mathrm{HIP} * 19)+\left(\mathrm{USO}^{*} 12\right) / 100$ 
Tabela 5: Influências e Pesos para a Integração dos Dados - Álgebra de Mapas

\begin{tabular}{|c|c|c|c|c|}
\hline Mapas temáticos & Influência relativa & Reclassificação & Peso & Grau de suscetibilidade \\
\hline \multirow{3}{*}{ Declividade $\left({ }^{\circ}\right)$} & \multirow{3}{*}{$42 \%$} & $0-2$ & 5 & Muito alto \\
\hline & & $2-3$ & 3 & Médio \\
\hline & & $3-68,92$ & 1 & Muito baixo \\
\hline \multirow{4}{*}{$\begin{array}{l}\text { Distância euclidiana } \\
\text { dos corpos hídricos }\end{array}$} & \multirow{4}{*}{$27 \%$} & $30 \mathrm{~m}$ dos córregos $/ 300 \mathrm{~m}$ dos rios & 5 & Muito alto \\
\hline & & $300-400 \mathrm{~m}$ dos rios & 4 & Alto \\
\hline & & $400-700 \mathrm{~m}$ dos rios & 3 & Médio \\
\hline & & Área de estudo & 1 & Muito baixo \\
\hline \multirow{4}{*}{ Hipsometria } & \multirow{4}{*}{$19 \%$} & $885,01-890$ & 5 & Muito alto \\
\hline & & $890-900$ & 4 & Alto \\
\hline & & $900-910$ & 3 & Médio \\
\hline & & $910-1140$ & 1 & Muito baixo \\
\hline \multirow{6}{*}{ Uso e cobertura da terra } & \multirow{6}{*}{$12 \%$} & Área residencial & 5 & Muito alto \\
\hline & & Pouca residência & 4 & Alto \\
\hline & & Loteamentos & 3 & Médio \\
\hline & & Pastagem/Agricultura/Mineração & 2 & Baixo \\
\hline & & Áreas naturais & 1 & Muito baixo \\
\hline & & Águas continentais & 0 & Restrito \\
\hline Total & 100 & - & - & \\
\hline
\end{tabular}

O modelo foi validado a partir de dados primários coletados em campo e em entrevistas com moradores e dados secundários, como o Plano de Contingência da Defesa Civil Municipal (2015) e registros fotográficos em redes sociais e jornais locais.

\subsubsection{Elaboração do Cenário Gráfico da Cartografia de Síntese e as Estruturas Verticais e Horizontais do Ambiente na Paisagem Urbana}

Após a integração dos dados e elaboração do mapa síntese, foi organizado o cenário gráfico da Cartografia de Síntese com as áreas de suscetibilidade à inundação. As estruturas da paisagem buscaram representar as dimensões (x, y, z, t) e estruturas (verticais e horizontais) dos ambientes (ZACHARIAS; VENTORINI, 2021). Desse modo, as Escalas Taxonômicas (estruturas verticais) foram hierarquizadas em 6 classes, sendo: (5) muito alto; (4) alto; (3) média; (2) baixo; (1) muito baixo e (0) restrito. Ao passo que, os componentes e elementos geográficos (estruturas horizontais) foram reorganizados em subclasses, conforme as diferenças e semelhanças de UCT que individualizam os diferentes graus de susceptibilidades no ambiente da paisagem urbana.

\section{Resultados e discussões}

\subsection{Validação das bases e das influências}

A validação dos mapas de UCT foi efetuada por meio de dados coletados em campo e diferenciação dos locais se deu pelo grau de impermeabilização do solo e pela densidade de residências. Locais com loteamentos sem construções receberam peso menor do que as áreas já consolidadas, visto que, o grau de interferência, em relação à impermeabilização, é menos significativo. A aplicação da AHP para a modelagem das áreas de inundação no setor da Colônia do Marçal possibilitou a atribuição dos valores de pesos (influência) em cada variável utilizada para ser usada na álgebra de mapas. A Tabela 6 indica os valores de julgamentos da matriz de julgamento normalizada e o vetor de prioridade. Os valores em porcentagem, aplicados em cada mapa permitiram o autovalor da matriz ( $\lambda$ Máx), em que foi possível estabelecer o índice e a razão de consistência (equações 4 e 5), demonstrando a consistência dos valores julgados na matriz inicial.

A partir dessa análise, considerando a interpretação de cada uma das bases, o entendimento sistêmico que as mesmas condicionam, a interação com a espacialidade dos fenômenos ambientais estudados e as recidivas ocorrências na área, atribui-se confiabilidade aos mapas e sua utilização como base para as modelagens, análises e proposição de medidas mitigadoras. 
Tabela 6: Matriz normalizada para o cálculo do vetor de prioridade

\begin{tabular}{lccccccc}
\hline Critérios & DEC & DCH & HIP & UCT & $\begin{array}{c}\text { Vetor de } \\
\text { prioridade }\end{array}$ & $\begin{array}{c}\text { Pesos } \\
(\mathbf{\%})\end{array}$ & Autovalor \\
\hline DEC & 0,429 & 0,500 & 0,364 & 0,375 & 0,417 & $\mathbf{4 2}$ & 4,0860017 \\
DCH & 0,215 & 0,250 & 0,364 & 0,250 & 0,270 & $\mathbf{2 7}$ & 4,0993532 \\
HIP & 0,215 & 0,125 & 0,182 & 0,250 & 0,193 & $\mathbf{1 9}$ & 4,0309477 \\
UCT & 0,142 & 0,125 & 0,091 & 0,125 & 0,121 & $\mathbf{1 2}$ & 4,0571569 \\
\hline Soma & $\mathbf{1 , 0 0 0}$ & 1,000 & 1,000 & 1,000 & 1,000 & 100 & \\
\hline IMax & & & & & & & 4,0683649 \\
IC & & & & & & & 0,0227883 \\
RC & & & & & & & $\mathbf{0 , 0 2 5 3 2 0 3}$ \\
\hline
\end{tabular}

Onde: $\mathrm{DEC}=$ declividade, $\mathrm{DCH}=$ distância dos corpos hídricos, $\mathrm{HIP}=$ hipsometria e UCT $=$ uso e cobertura da terra. Fonte: Autores (2020)

\subsection{A Cartografia dinâmica e os modelos espaciais-temporais}

A análise comparativa do UCT dos anos de 1989 e 2020 juntamente com a tabulação cruzada das classes, indicam que $60 \%$ da cobertura vegetal existente em 1989 foi suprimida e substituída, majoritariamente, por áreas agrícolas (agricultura e pastagem) e edificações oriundas da expansão urbana. Quantitativamente, a análise indica que entre 1989 e 2020 o perímetro urbano do Setor Colônia do Marçal aumentou em 320\%. Este aumento ocorreu em detrimento da abertura de loteamentos e áreas residenciais com maior e menor densidade.

Segundo Andrade (2014), a expansão imobiliária do Setor ocorreu, principalmente, a partir dos anos 2000, quando a forte especulação induziu a abertura de loteamentos e criação de condomínios fechados, consequentemente, a ampliação das infraestruturas urbanas e elevação no valor dos imóveis. Estas mudanças no UCT, sobretudo no que se refere à expansão das áreas urbanizadas, refletem diretamente na dinâmica natural do Setor. Observa-se que essa expansão ocorreu, sobretudo, em direção e sobre os córregos, na faixa altimétrica de $890 \mathrm{~m}$ a $935 \mathrm{~m}$, onde as declividades variam entre $0^{\circ}$ e $10^{\circ}$ (Figura 2). De forma menos concentrada, a expansão também ocorreu sobre áreas localizadas em faixas altimétricas abaixo de 890m e entre $940 \mathrm{~m}$ e $1010 \mathrm{~m}$. Nessas áreas mais elevadas, a declividade aumenta e varia entre $8^{\circ}$ até $33^{\circ}$.

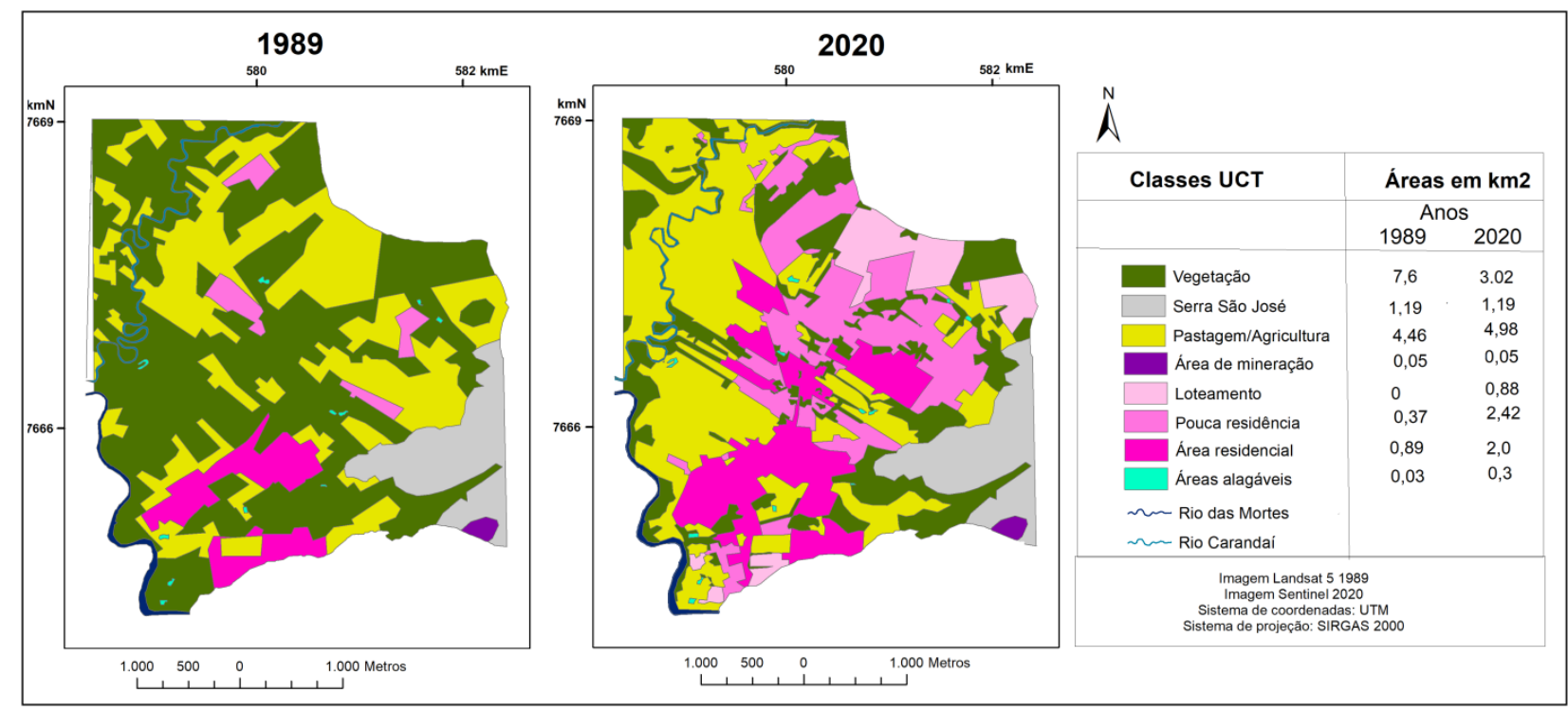

Figura 2: Mapas de Usos e Cobertura da Terra (1989 e 2020). Fonte: Autores (2020)

A ocupação e impermeabilização dessas áreas a montante impactam diretamente o sistema de drenagem a jusante, pois aumentam o escoamento superficial e propiciam o acúmulo de águas pluviais e saturação de canais nas áreas pouco declivosas e tendenciosamente ocupadas. Como consequência das mudanças no UCT, as modelagens comparativas dos anos de 1989 e 2020 sofreram modificações e áreas classificadas como muito baixa e média no cenário de 1989, reduziram, respectivamente, $3 \%\left(0,21 \mathrm{~km}^{2}\right)$ e $42 \%\left(1,33 \mathrm{~km}^{2}\right) \mathrm{na}$ comparação com o cenário de 2020. As demais classes, grau baixo, alto e muito alto aumentaram $0,05 \mathrm{~km}^{2}$, $1,3 \mathrm{~km}^{2}$ e $0,14 \mathrm{~km}^{2}$, respectivamente. As análises indicam que, apesar da considerável expansão do Setor Censitário em análise, a classe muito alta suscetibilidade aumentou apenas 7,2\%, tendo em vista a 
inexistência de ocupação na planície de inundação dos rios Carandaí e das Mortes. Em contrapartida, a classe de alta suscetibilidade aumentou 58,7\% (Figura 3).

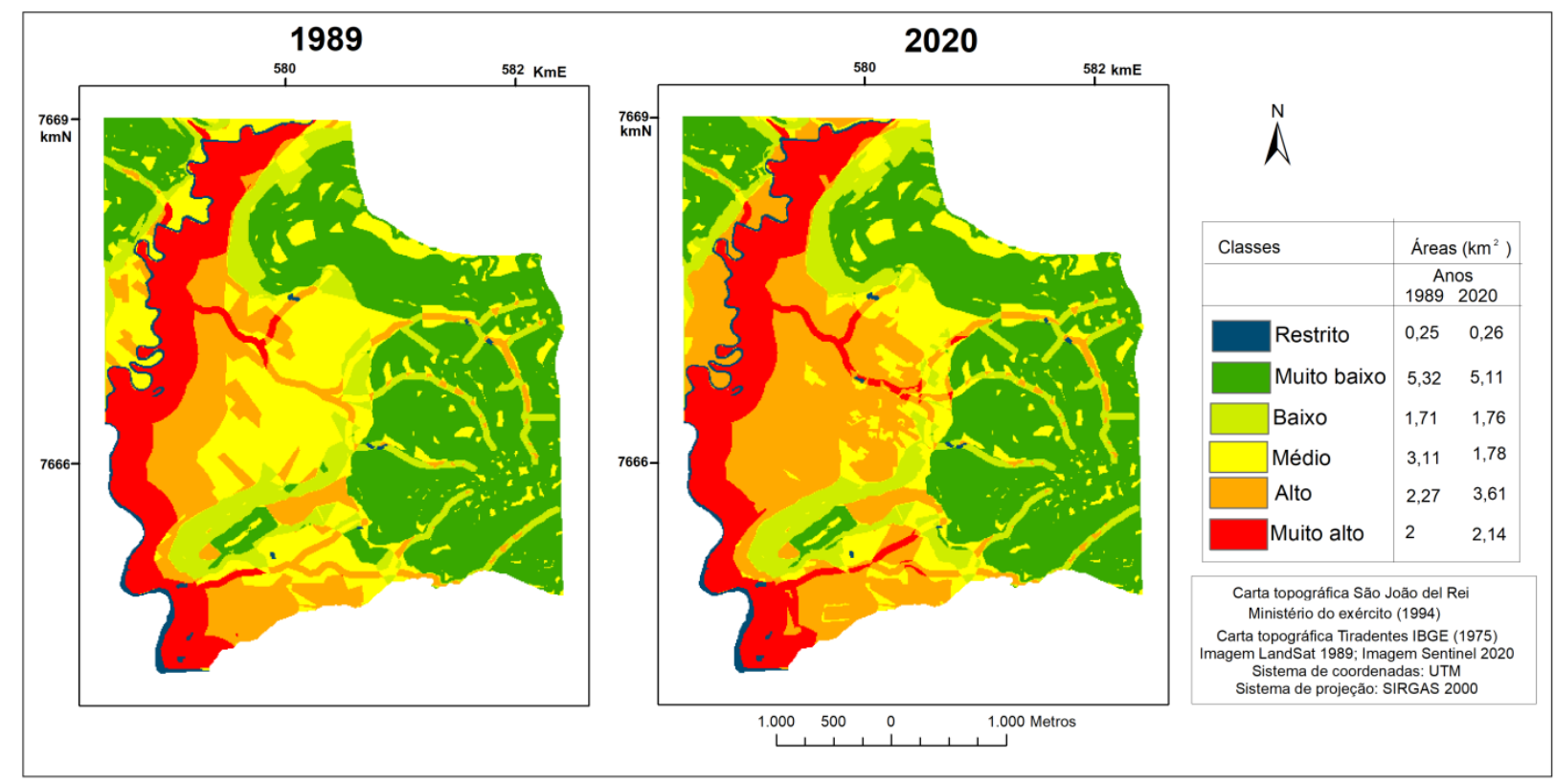

Figura 3: Mapas de Susceptibilidades à Inundação (1989 e 2020). Fonte: Autores (2020)

Em uma análise comparativa, os dois anos apresentam diferenças entre classes de: a) $0,21 \mathrm{~km}^{2} \mathrm{e} 0,05 \mathrm{~km}^{2}$ nas classes muito baixa e baixa, indicando que o setor cresceu para áreas favoráveis à moradia; b) $1,33 \mathrm{~km}^{2}$ para áreas com média suscetibilidade às inundações, ou seja, para áreas que, apesar de distantes de corpos hídricos, a declividade baixa aliada a infraestrutura precária ocasiona a possibilidade da chegada das águas fluviais e; c) $1,34 \mathrm{~km}^{2}$ e $0,14 \mathrm{~km}^{2}$ para áreas com suscetibilidade alta e muito alta às inundações, indicando o crescimento desordenado para áreas que deveriam ser protegidas por lei e/ou terraços fluviais.

A análise das alterações de graus de suscetibilidade dentro da mancha urbana da área aponta que em 1989, 0,198 $\mathrm{km}^{2}$ da área urbana estava consolidada em locais com grau de suscetibilidade muito baixo e $0,346 \mathrm{~km}^{2} \mathrm{em}$ locais de grau baixo. As classes de médio e alto grau compunham $0,131 \mathrm{~km}^{2}$ e $0,566 \mathrm{~km}^{2} \mathrm{da}$ área em análise, enquanto a classe de grau muito alto representava apenas $0,012 \mathrm{~km}^{2}$. A partir do crescimento da mancha urbana do Setor, que passou de $1,25 \mathrm{~km}^{2} \mathrm{em} 1989$ para 5,28 km² em 2020, houve alterações nessa relação. Atualmente, as áreas com graus de suscetibilidade muito baixo e baixo compreendem, respectivamente, $1,942 \mathrm{~km}^{2}(36,78 \%)$ e $0,635 \mathrm{~km}^{2}(12,02 \%)$ do limite urbano. As áreas de média suscetibilidade passaram a constituir $0,747 \mathrm{~km}^{2}(14,15 \%)$, enquanto as áreas de alta e muito alta suscetibilidade, $1,665 \mathrm{~km}^{2}(31,53 \%)$ e $0,291 \mathrm{~km}^{2}(5,51 \%)$.

\subsection{A Cartografia de síntese e o estado ambiental das áreas susceptiveis às inundações}

A aplicação do método da Cartografia de Síntese e o diagnóstico do estado ambiental contribuíram para identificação dos principais problemas referentes à suscetibilidade às inundações no Setor Censitário Colônia do Marçal. A partir dessa perspectiva, o estudo mostra-se passível de subsidiar políticas públicas municipais que visem a mitigação e prevenção aos processos e danos, bem como auxílio para a revisão do Plano Diretor Municipal (Figura 4).

Observa-se que o desenvolvimento da técnica empregada depende da percepção, observação, interpretação e sistematização dos processos naturais e condicionantes estruturais que influenciam na qualidade de vida da população e, também, recebem intervenção direta desta. 

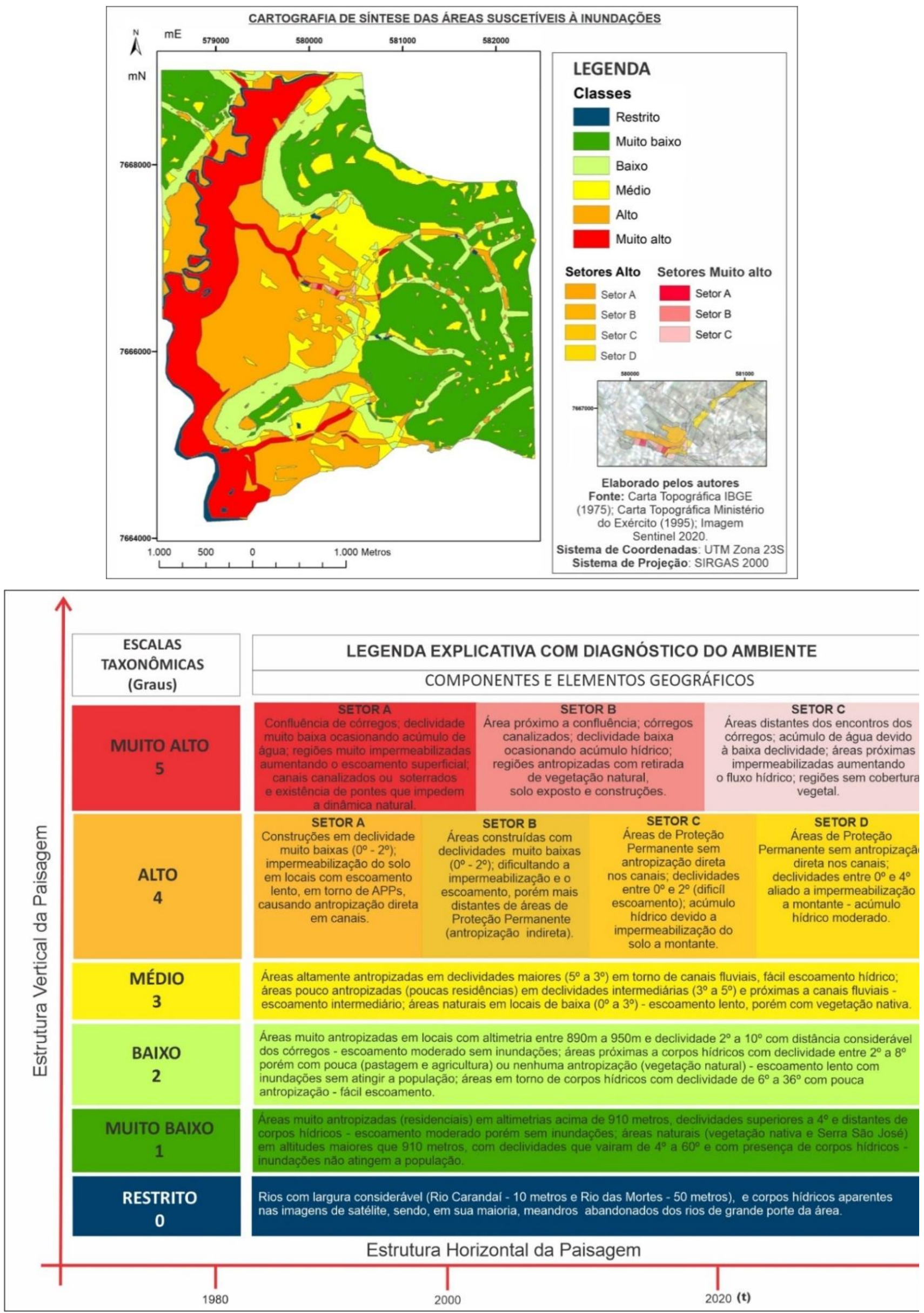

Figura 4: Cartografia de Síntese das Áreas com Suscetibilidades às Inundações - 2020. Fonte: Autores (2020). 
O cenário gráfico elaborado no mapa síntese permite observar a influência e dinâmica dos fluxos de energia, matéria e informação (EMI) do meio, sobretudo quando se refere a interações na bacia hidrográfica. Estas influências e dinâmicas foram denominadas aqui como estruturas verticais e horizontais. As estruturas verticais indicaram a hierarquização de 6 classes taxonômicas - muito alto (5), alto (4), médio (3), baixo (2), muito baixo (1) e restrito (0) - definidas conforme o grau de importância e a intensidade do ambiente ao fenômeno de inundação. Ao passo que, as estruturas horizontais, a partir da reclassificação, também resultaram em 6 taxonomias, ou classes, referentes ao UTC. Estas evidenciaram intensidades variadas nos graus de suscetibilidades, o que possibilitou a hierarquização do cenário gráfico de forma similar à dinâmica que compõe, interfere, modela e modifica o meio em análise.

A partir dessa individualização dos cenários, foi possível descompartimentar as áreas classificadas como alto e muito alto, atribuindo-lhes subclasses que permitem pormenorizar as diferentes intensidades que o fenômeno atinge. Desse modo, a classe de grau muito alto passou a ser composta por três subclasses denominadas Setor A, Setor B e Setor C, ou seja, a classe principal foi setorizada em três grupos caracterizados por áreas com baixas declividades $\left(\begin{array}{lll}0 & \text { a } & 2^{\circ}\end{array}\right)$, ausência de vegetação natural devido a urbanização, impermeabilização das vias e consequente acúmulo dos fluxos hídricos que escoam rapidamente e concentram-se. A classe de alto grau de suscetibilidade foi setorizada em Setor A, Setor B, Setor C e Setor D, os quais possuem baixas declividades $\left(0\right.$ a $\left.4^{\circ}\right)$, avanço da urbanização sobre a vegetação nativa e áreas de preservação, impermeabilização das vias e consequente acúmulo dos fluxos hídricos. Os setores de médio, baixo e muito baixo grau de suscetibilidade mantiveram a homogeneidade das classes contidas nas estruturas vertical e horizontal da paisagem.

De modo geral, os dados obtidos indicam que os bairros do Setor Censitário Colônia do Marçal passaram, nas últimas décadas, por uma significativa expansão que não respeitou os limites da dinâmica natural do sistema. Devido a isso, a cada período chuvoso, a população local vivencia o transtorno causado por inundações e alagamentos que ocorrem, sobretudo, nas vias situadas em áreas com baixas declividades (entre $0^{\circ}$ e $\left.3^{\circ}\right)$.

Conforme os registros da Defesa Civil Municipal (2015), 50\% dos registros dos fenômenos supracitados (inundações e alagamentos), em São João del-Rei, ocorreram no Setor Colônia do Marçal, notabilizando-se por 5 (cinco) vezes frente seus índices de mensuração e classificação dos graus de riscos à inundação (Tabela 7).

Tabela 7: Classificação dos Graus de Riscos à Inundação

\begin{tabular}{|c|l|}
\hline Graus de risco & \multicolumn{1}{|c|}{ Descrição } \\
\hline Baixo & $\begin{array}{l}\text { Sistema de drenagem/taludes com baixo potencial a causar danos e baixa frequência de } \\
\text { ocorrência (sem registros de ocorrência nos últimos 5 anos). }\end{array}$ \\
\hline Médio & $\begin{array}{l}\text { Sistema de drenagem/taludes com médio potencial a causar danos e média frequência de } \\
\text { ocorrência (uma ocorrência significativa nos últimos 5 anos). }\end{array}$ \\
\hline Alto & $\begin{array}{l}\text { Sistema de drenagem/taludes com médio potencial a causar danos e média frequência de } \\
\text { ocorrência (uma ocorrência significativa nos últimos 5 anos) envolvendo moradias de alta } \\
\text { vulnerabilidade. }\end{array}$ \\
\hline Muito alto & $\begin{array}{l}\text { Sistema de drenagem/taludes com alto potencial a causar danos e alta frequência de } \\
\text { ocorrência (pelo menos três ocorrências significativas nos últimos 5 anos) envolvendo } \\
\text { moradias de alta vulnerabilidade. }\end{array}$ \\
\hline
\end{tabular}

Fonte: BRASIL (2007)

Ao posicionar os registros dos locais com inundações disponibilizados pela Defesa Civil no modelo ambiental do cenário presente (2020), bem como os registros de ocorrências publicados em jornais locais e/ou por moradores, verifica-se a veracidade das classes taxonômicas identificadas que compõem a estrutura vertical da paisagem.

Nessa lógica, um dos pontos mais problemáticos é a Avenida Luís Giarola, a qual dá acesso a diversos bairros e possui fluxo intenso de veículos. A amplitude altimétrica e os desníveis ao longo desta via são significativos no local. Além disso, há um curso d'água que acompanha a via, propiciando o acúmulo de água devido ao ângulo côncavo, a baixa declividade e recebimento das águas de um afluente. Fatos que somados à precária infraestrutura resultam em recorrentes inundações durante os eventos chuvosos (Figura 5). A Tabela 8 possibilita avaliar e sintetizar o Estado, o Diagnóstico, os Riscos e Problemas Ambientais, considerando as estruturas vertical e horizontal do ambiente na paisagem do Setor Censitário Colônia do Marçal. 


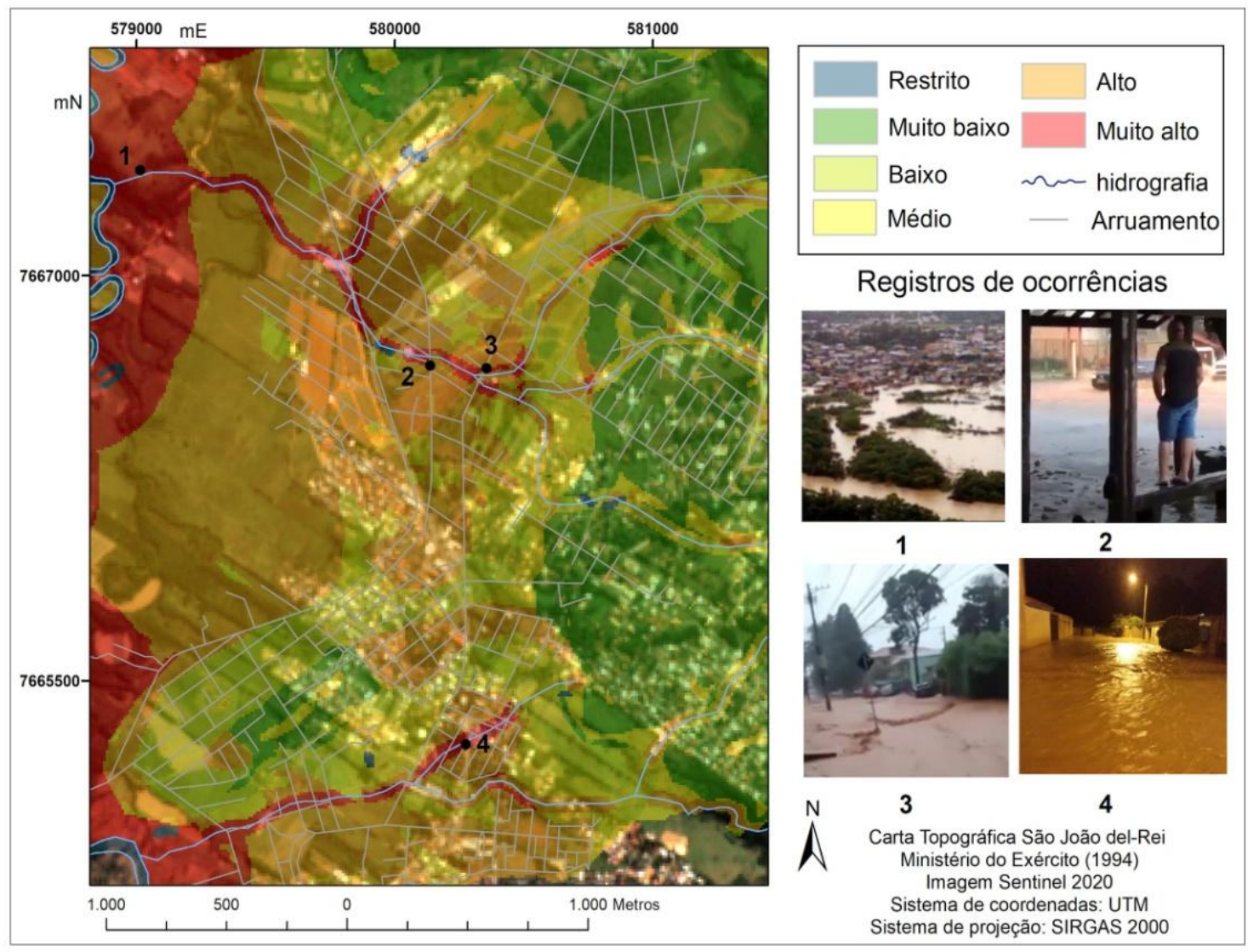

Figura 5: Registro de Ocorrências de Inundação - 2020. Fonte: Autores (2020)

Tabela 8: Estado, Diagnóstico Riscos e Problemas Ambientais na Área de Estudo

\section{Estrutura}

Vertical

Alto

Alto

Médio,

Baixo e

Muito

baixo

\section{Estrutura Horizontal}

Estado e diagnóstico ambiental

Riscos e problemas ambientais

Área acumuladora de fluxos hídricos e altamente suscetível a inundações; Caracterizam-se como planícies fluviais; Coletam e acumulam fluxos de energia, matéria e informação (EMI); Possuem a função de transmitir, de forma concentrada e seletiva, energia e matéria por meio dos fluxos hídricos, o que garante a comunicação com as partes inferiores (áreas restritas) e médias da bacia; Paisagens dinâmicas e em constante evolução devido as interferências do meio urbano.

Área transmissora e com alta suscetibilidade a inundações; Predominantemente composta por superfícies aplainadas e sopés de vertentes, as quais garantem o translado dos fluxos e EMI; Paisagens sob interferência da urbanização, contendo superfícies impermeabilizadas que potencializam o rápido acúmulo; Presença de área agrícolas, sobretudo, nas faixas de transição com a zona de muito alta suscetibilidade.

Áreas emissoras e com média a muito baixa suscetibilidade a inundação; Garantem os fluxos de EMI para o restante do sistema em análise; São áreas topograficamente mais elevadas, onde predomina o processo de sedimentação em detrimento a deposição.
Grandes proporções de áreas com inundações; concentração de enchentes; desmoronamento de margens; poluição dos cursos d'água e, consequentemente, do lençol freático; assoreamento; extinção da ictiofauna e perdas de patrimônio urbano, habitações, infraestruturas, áreas verdes e de lazer.

Grandes proporções de áreas com inundações; concentração de enchentes; desmoronamento de margens; assoreamento; poluição dos cursos d'água e, consequentemente, do lençol freático.

Pequenas proporções de áreas sujeitas a inundações; supressão da vegetação natural devido ao avanço urbano; 
Diante do apresentado, é substancial que a Gestão Pública do município de São João del-Rei reavalie sua legislação, sobretudo no que se refere à concessão de licenças ou alvará para novos loteamentos e/ou construções no setor de Colônia do Marçal, uma vez que: a) no período de 1989-2020 a área urbana apresentou expansão significativa, principalmente sobre áreas com alta e muito alta suscetibilidade as inundações; b) a Lei Federal $\mathrm{n}^{\mathrm{o}} 12.608 / 12$ determina novas diretrizes para municípios quanto ao planejamento urbano (Estatuto da Cidade - Lei Federal $n^{\circ}$ 10.257/01) e ao uso e ocupação da terra (Lei de Parcelamento do Solo Urbano - Lei Federal nº 6.766/79).

Além disso, faz-se necessário a (re)discussão e (re)análise do Plano Diretor Municipal Participativo, bem como a elaboração de cenários futuros em escala detalhada, a fim de obter prognósticos que auxiliem a gestão e o planejamento ambiental. Estes cenários devem considerar, por exemplo:

1.': Como estará o Setor Colônia do Marçal dentro de alguns anos (5, 10, 20, etc.) caso não sejam implementadas medidas de mitigação aos processos de inundação;

2. : Como estará o Setor Colônia do Marçal dentro de alguns anos (5, 10, 20, etc.) caso sejam implementadas, parcialmente, medidas de mitigação aos processos de inundação;

3. ${ }^{\circ}$ : Como estará o Setor Colônia do Marçal dentro de alguns anos (5, 10, 20, etc.) caso sejam implementadas todas as medidas de mitigação aos processos de inundação e melhoria do Estado Ambiental.

A modelagem desses cenários permitirá estabelecer restrições e potencialidades de ocupação da área, o que conduzirá estudos sobre saneamento, drenagem, escavações e fundações, impermeabilizações, coeficiente de aproveitamento, e outros.

\section{Considerações finais}

A partir dos levantamentos realizados pode-se constatar que o crescimento das cidades desvinculado de um planejamento ambiental vem ocasionar diversos impactos ambientais e sociais no ambiente, modificando estruturalmente a paisagem e a dinâmica fluvial, além de ressignificar a relação entre humanidade e natureza. Assim, a expansão da área urbana e consequentes intervenções antrópicas nos canais e cobertura da terra fizeram com que os graus de suscetibilidade às inundações aumentassem, sobretudo em locais com o sistema de drenagem com médio e alto potencial a causar danos, além da frequência média ou alta de ocorrências.

Os dois modelos espaciais temporais (1989 e 2020) obtidos pela análise multicritério AMD e AHP, apresentam áreas de muito alta suscetibilidade em alguns locais em comum, já que apesar da expansão dos bairros do Setor, a planície dos dois rios de grande porte (Carandaí e das Mortes) não alteraram os cenários, independente das de construções que potencializam as inundações. Além disso, em torno de outros canais fluviais de menor dimensão, que foram antropizados e apresentam baixa declividade, as classes alta e muito alta são frequentes em detrimento de sua dinâmica natural de inundação.

Por fim, a Cartografia de Síntese assumiu sua conotação relevante, uma vez que, acompanhada pela legenda descritiva e propositiva dos diferentes ambientes que compõem a paisagem no real, auxiliou na ordenação, classificação, divisão e integração das informações que correspondem as escalas taxonômicas (estrutura vertical) e os diferentes elementos e atributos dos componentes geográficos (estrutura horizontal) da paisagem, inseridos nas dimensões $(\mathrm{x}, \mathrm{y}, \mathrm{z}, \mathrm{t})$ do mapa.

\section{Notas}

O programa ARC-GIS Versão 10. 7 utilizado neste estudo utiliza a Licença institucional Universidade Federal de São João del-Rei - Laboratório de Cartografia, Geoprocessamento, Sensoriamento Remoto - Labcar - DEGEO - UFSJ. Versão 10.8.1 - Licença institucional da Universidade Estadual Paulista aberta à docentes e alunos.

\section{Agradecimentos}

O presente trabalho foi realizado com apoio da Coordenação de Aperfeiçoamento de Pessoal de Nível Superior - Brasil (CAPES) - Código de Financiamento 88882.434000/2019-1; 88887.607668/2021-00 - e Universidade Federal de São João del-Rei - Programa Institucional de Iniciação Científica. 
Referências bibliográficas

AUMOND, J. J.; LOCH, C.; COMIN, J. J. Abordagem sistêmica e o uso de modelos para recuperação de áreas degradadas. Revista Árvore, Viçosa, v. 36, n. 6, p. 1099-1118, 2012. Acesso em: 11 mai. 2021.

BRASIL. Lei $\mathrm{n}^{\circ}$. 10.257/2001 - Estatuto da Cidade. Disponível em: <http://www.planalto.gov.br/ccivil 03/leis/LEIS 2001/L10257.htm>. Acesso em: 10 mai 2021

BRASIL. Lei ${ }^{\circ}$ 12608, de 10 de abril de 2012. Política Nacional de Proteção e Defesa Civil - PNPDEC. Brasília, 2012. Disponível em: <http://www.planalto.gov.br/ccivil_03/_Ato20112014/2012/Lei/L12608.htm>. Acesso em: 10 mai. 2021.

BRASIL. Ministério das Cidades. Mapeamento de riscos em encostas e margem de rios. CARVALHO, C. S.; MACEDO, E. S. de; OGURA, A. T. (orgs). Brasília: Ministério das Cidades; Instituto de Pesquisas Tecnológicas - IPT, 2007.

BRAZ, A. M. Zoneamento Turístico das Paisagens para o Município de Mineiros (GO), Brasil. 2020. 354f. Tese (Doutorado em Geografia). Programa de Pós-Graduação em Geografia. Universidade Federal de Goiás/Regional Jataí. Jataí/GO, 2020.

CAVALCANTI, L. C. S. Da descrição de áreas à Teoria dos Geossistemas: uma abordagem epistemológica sobre sínteses naturalistas. 2013. 218 f. Tese (Doutorado em Geografia). Programa de Pós-Graduação em Geografia - Universidade Federal de Pernambuco (UFPE). Recife/PE, 2013.

FADHIL, M.; RISTYA, Y.; OKTAVIANI, N.; KUSRATMOKO, E. Flood vulnerability mapping using the spatial multi-criteria evaluation (SMCE) method in the Minraleng Watershed, Maros Regency, South Sulawesi. E3S Web of Conferences, [S.L.], v. 153, p. 1-7, 2020. EDP Sciences. <http://dx.doi.org/10.1051/e3sconf/202015301004> Acesso em: 11 mai. 2021.

FERNÁNDEZ, D.s.; LUTZ, M.A. Urban flood hazard zoning in Tucumán Province, Argentina, using GIS and multicriteria decision analysis. Engineering Geology, [S.L.], v. 111, n. 1-4, p. 90-98, 2010. Elsevier BV. <http://dx.doi.org/10.1016/j.enggeo.2009.12.006> Acesso em: 11 mai. 2021.

FLORENZANO, T. G. Cartografia. Geomorfologia: conceitos e tecnologias atuais. São Paulo: Oficina de Textos, 2008.

HOANG, V. D.; TRAN, H. T; NGUYEN, T. T. A GIS-based Spatial Multi-criteria Approach for Flash Flood Risk Assessment in the Ngan Sau-Ngan Pho Mountainous River Basin, North Central of Vietnam. Environment and Natural Resources Journal, Thailand., v., n. 18, 110-123, 2020. Disponível em: 〈https://ph02.tci-thaijo.org/index.php/ennrj/index>. Acesso em: 15 set. 2020.

GARCIA, P. M. B.; AUGUSTIN, C. H. R. R.; CASAGRANDE, P. B. Índice geomorfológico como subsídio ao planejamento urbano. Mercator, Fortaleza, v. 19, n. 2, p. 1-27, 2020. Disponível em: <http://www.mercator.ufc.br/mercator>. Acesso em: 08 jun. 2020.

GIGOVIC, L.; PAMUCAR, D.; BAJIC, Z.; DROBNJAK, S. Application of GIS-Interval Rough AHP Methodology for Flood Hazard Mapping in Urban Areas. Water, [S.L.], v. 9, n. 6, p. 1-26, 24 maio 2017. MDPI AG. <http://dx.doi.org/10.3390/w9060360> Acesso em: 20 fev. 2020.

GIRÃO, O; CORREA, A. C. B. A contribuição da geomorfologia para o planejamento da ocupação de novas áreas. Revista de Geografia. Recife, v. 21, n. 2, p. 36-58, 2004 . Disponível em < https://periodicos.ufpe.br/revistas/revistageografia > Acesso em: 02 jun de 2019.

IBGE, Instituto Brasileiro de Geografia e Estatística. Censo Demográfico 1980. Disponível em: < https://biblioteca.ibge.gov.br/visualizacao/periodicos/72/cd_1980_v1_t4_n16_mg.pdf > Acesso em: 10 fev. 2021.

IBGE, Instituto Brasileiro de Geografia e Estatística. Censo Demográfico 2010. Disponível em: <www.censo2010.ibge.gov.br > Acesso em: 10 fev. 2021. 
IGAM, Instituto Mineiro de Gestão das Águas. Disponível em: www.igam.mg.gov.br. Acesso em: 13 abr. 2020.

MATERANO, L. S.; BRITO, J. L. S. Fragilidade ambiental potencial da bacia hidrográfica do Rio Castán, estado Trujillo - Venezuela. Caminhos de Geografia, v.21, n.73, p. 86-97, 2020. http://dx.doi.org/10.14393/rcg217347216.

OGATO, G. S. et al. Geographic information system (GIS)-Based multicriteria analysis of flooding hazard and risk in Ambo Town and its watershed, West shoa zone, oromia regional State, Ethiopia. Journal Of Hydrology: Regional Studies, v. 27, p. 1-18, 2020. http://dx.doi.org/10.1016/j.ejrh.2019.100659.

OWENS, S., COWELL, R. Land and limits: interpreting sustainability in the planning process. Routledge, 2001.

RAHMATI, O.; ZEINIVAND, H.; BESHARAT, M. Flood hazard zoning in Yasooj region, Iran, using GIS and multi-criteria decision analysis. Geomatics, Natural Hazards And Risk, [s.1.], v. 7, n. 3, p. 1000-1017, 2015. DOI: http://dx.doi.org/10.1080/19475705.2015.1045043.

REANI, T. R.; SORIANO, E.; LONDE, L. R.; TOMÁS, R. L.; VIANNA, M. L. N. G.; SANTOS, L. B. L. Interfaces legais entre planejamento urbano e redução de riscos e desastres. Caminhos de Geografia, Uberlândia-MG, v. 21, n. 7, p. 116-133. 2020. DOI: https://doi.org/10.14393/RCG217651879.

RIBEIRO, M. C. de C. R.; ALVES, A. da S. Aplicação do método Analytic Hierarchy Process (AHP) com a mensuração absoluta num problema de seleção qualitativa. Sistemas \& Gestão, v. 11, n. 3, p. 270-281, 2016. DOI: http://dx.doi.org/10.20985/1980-5160. 2016.

RIMBA, A.; SETIAWATI, M.; SAMBAH, A.; MIURA, F. Physical Flood Vulnerability Mapping Applying Geospatial Techniques in Okazaki City, Aichi Prefecture, Japan. Urban Science, v. 1, n. 1, p. 1-22, 2017. DOI: http://dx.doi.org/10.3390/urbansci1010007

SAATY, T. L. Analytic Hierarchy Process. Encyclopedia Of Biostatistics. p. 1-9, 15. 2005. DOI: http://dx.doi.org/10.1002/0470011815.b2a4a002.

SAATY, T. L. The Analytic Network Process. Decision Making With the Analytic Network Process. Springer. p. 1-26, 2006. DOI: http://dx.doi.org/10.1007/0-387-33987-6 1.

SANDER, C. et al. Intervenções antrópicas em canais fluviais em áreas urbanizadas. Revista Acta Geográfica, Boa Vista, p.59-84, ago. 2012. Revista ACTA Geográfica. DOI: http://dx.doi.org/10.5654/actageo2012.0612.0004.

SANTOS, T. G.; VENTORINI, S. E. Análise multicritério: modelos de interesse ambiental e de áreas propícias à expansão urbana na bacia do Córrego do Lenheiro. Caminhos da Geografia, Uberlândia, v. 9, n. 64, p. 1-18, dez. 2017a. <http://www.seer.ufu.br/index.php/caminhosdegeografia/article/view/40912/21635>. Acesso em: 16 mai. 2020.

SANTOS, T. G.; VENTORINI, S. Mapeamento de áreas suscetíveis aos desastres humanos de natureza na bacia do Córrego do Lenheiro, Minas Gerais, Brasil. Revista Venezolana de Geografia, Mérida, v. 59, n. 1, p. 162-181, jun. 2018. <http://www.saber.ula.ve/handle/123456789/44700>. Acesso em: 16 mai. 2020.

VARGAS, R.V. Utilizando a programação multicritério (Analytic Hierarchy Process - AHP) para selecionar e priorizar projetos na gestão de portfólio. PMI Global Congress - América do Norte. 2010. Washington - EUA. Disponível em https://ricardo-vargas.com/pt/downloads/download-file/6103/6816. Acesso em: 27 ago. de 2020).

ZACHARIAS, A. A. Zoneamento ambiental e a representação cartográfica das unidades de Paisagens: propostas e subsídios para o Planejamento Ambiental do município de Ourinhos -SP. 2006. 200f. Tese (Doutorado em Geografia). Programa de Pós-Graduação em Geografia - IGCE - UNESP/Rio Claro/SP. 2006. 
ZACHARIAS, A. A. A representação gráfica das unidades de paisagem no zoneamento ambiental. Editora Unesp. São Paulo. 2010.

ZACHARIAS, A. A.; VENTORINI, S. E. A Cartografia de síntese, o ambiente e a paisagem: caminhos, desafios, perspectivas e proposta metodológica. PUBLICAÇÕES AVULSAS: Geografia, UFPI, Teresina/PI, vol. 22, n. 3, p. 120-157. 2021 (in press).

$10 \begin{aligned} & \text { Este artigo é distribuído nos termos e condições do Creative Commons Attributions/Atribuição- } \\ & \text { NãoComercial-CompartilhaIgual (CC BY-NC-SA). }\end{aligned}$ 